\title{
Site-selected luminescence of atomic europium in the solid rare gases
}

\author{
Owen Byrne and John G. McCaffrey ${ }^{\mathrm{a})}$ \\ Department of Chemistry, National University of Ireland - Maynooth, Maynooth, County Kildare, Ireland
}

(Received 3 May 2011; accepted 20 June 2011; published online 12 July 2011)

\begin{abstract}
Site-selective excitation has been used to simplify complex emission recorded in the visible spectral region for atomic europium isolated in the solid rare gases. In addition to $y^{8} \mathrm{P}$ resonance fluorescence, excitation of the $y^{8} \mathrm{P}$ state produces emission from the $z^{6} \mathrm{P}$ state and the metastable $a^{10} \mathrm{D}$ state. Very weak emission at $690 \mathrm{~nm}$ is tentatively assigned to the $\mathrm{J}=9 / 2$ level of the $z^{10} \mathrm{P}$ state. Eu atoms isolated in the red and blue sites exhibit very different temperature dependence both spectrally and temporally. For the $y^{8} \mathrm{P}$ state emission the red site atoms exhibit small Stokes shifts and yield radiative lifetimes while the emission from the blue site loses intensity and the temporal profiles shorten dramatically between 10 and $16 \mathrm{~K}$ indicating very efficient non-radiative relaxation in this site. An analysis of the Stokes shifts exhibited for the $y^{8} \mathrm{P}$ state in each site supports the attributions made in a previous publication [O. Byrne and J.G. McCaffrey, J. Chem. Phys. 134, 124501 (2011)] that the smaller blue tetravacancy site has a greater repulsive interaction with the guest. With the exception of the $y^{8} \mathrm{P}$ state resonance fluorescence, the recorded decay profiles of all the other emissions exhibit multiple components. This behaviour has been attributed to the existence of multiple crystal field levels arising from the splitting of the distinct spin-orbit levels from which emission occurs. (c) 2011 American Institute of Physics. [doi:10.1063/1.3609116]
\end{abstract}

\section{INTRODUCTION}

In a recent study ${ }^{1}$ of the absorption spectroscopy of matrix-isolated europium $(\mathrm{Eu} / \mathrm{RG})$ multiple trapping sites were observed for the atom isolated in the solid rare gases (RG) for spectra recorded in the $y^{8} \mathrm{P}$ state region. Two thermally stable sites were identified for Eu atoms in $\mathrm{Ar}$ and $\mathrm{Kr}$ matrices, while upon annealing only a single site remained in xenon. From polarisability plots of the observed matrix shifts, the higher energy "blue" sites in Ar and $\mathrm{Kr}$ are associated with the single site present in Xe. Based on estimates of the Eu-RG diatomic bond lengths, this site is postulated to be a tetra-vacancy while the lower energy "red" site, present only in $\mathrm{Ar}$ and $\mathrm{Kr}$, is proposed to be a hexa-vacancy. The site labels "red" and "blue" pertain to the relative positions of these bands in the absorption spectra of the resonance $y^{8} \mathrm{P}$ state. Detailed analyses of this and the near-UV ${ }^{8} \mathrm{P}$ state absorption spectroscopy have recently been presented in Ref. 1, hereafter referred to as Paper I.

Figure 1 presents an energy level diagram for the possible transitions in the visible spectral region of gas phase ${ }^{2}$ atomic Eu. With an $a^{8} \mathrm{~S}$ ground state, two strong absorptions are expected, namely to the $z^{8} \mathrm{P}$ and the $y^{8} \mathrm{P}$ states. However, as indicated on the left of Fig. 1, only the latter transition at $466.32 \mathrm{~nm}$ has a large oscillator strength with a gas phase lifetime of $7.7 \mathrm{~ns}$. To date, no work has been presented in the literature for the luminescence of matrix-isolated atomic $\mathrm{Eu}$ in the visible spectral region, which has a rich electronic structure consisting of $\mathrm{P}$ and $\mathrm{D}$ term manifolds. In the present study we analyse the emission produced with excitation of the resonance $y^{8} \mathrm{P} \leftarrow a^{8} \mathrm{~S}$ transition. In addition, a previously undocumented $6 \mathrm{~s}^{1} 6 \mathrm{p}^{1} \mathrm{z}^{6} \mathrm{P}$ state is analysed in newly obtained

\footnotetext{
${ }^{\text {a)} E l e c t r o n i c ~ m a i l: ~ j o h n . m c c a f f r e y @ n u i m . i e . ~}$
}

excitation spectra. The present study aims to obtain state assignments for the observed emission bands, probe the relaxation amongst the $\mathrm{P}$ and $\mathrm{D}$ electronic states and using a combination of observed matrix shifts and estimates of the Eu-RG nearest neighbour distances, possible site occupancies for the metal atom will be considered and discussed.

\section{EXPERIMENTAL}

Samples were deposited ${ }^{3,4}$ as described in Paper I at $10 \mathrm{~K}$ at gas flow rates of $3 \mathrm{mmol} / \mathrm{h}$ for periods of $30 \mathrm{~min}$. To simplify the site occupancy, they were then annealed to 26,36 , and $60 \mathrm{~K}$ for $\mathrm{Ar}, \mathrm{Kr}$ and $\mathrm{Xe}$, respectively. The luminescence spectra reported in this study were recorded in the most dilute $\mathrm{Eu} / \mathrm{RG}$ samples formed, which are known from the absorption spectra analysed in Paper I, to contain only atomic euopium. Unless stated otherwise, all spectra were recorded at $10 \mathrm{~K}$.

Continuous photoexcitation was produced with a tungsten lamp (UV/Vis 300 to $900 \mathrm{~nm}$ range) while specific wavelengths were selected using a $0.3 \mathrm{~m}$ monochromator (Acton Research Corporation, model SpectraPro-300i) containing a 1200 grooves $/ \mathrm{mm}$ diffraction grating blazed at $300 \mathrm{~nm}$. Emission was monitored perpendicular to the light source and wavelengths of interest were selected using a $0.5 \mathrm{~m}$ monochromater (ARC, model SP500i) fitted with three gratings. Emission intensities were monitored using a photon counting (Hamamatsu, model R928-P) PMT detector operated at $-20^{\circ} \mathrm{C}$ in a cooled housing (Photocool, model S600) or an intensified charge coupled device (iCCD) detector (Andor Technologies, model iStar DH720) held at $-15^{\circ} \mathrm{C}$ by an integrated Peltier cooling system. The detector of choice was selected by a swing mirror in the SP500i, which allowed the dispersed emitted radiation either to fall directly on the 


\section{Gas Phase energy levels of atomic europium}

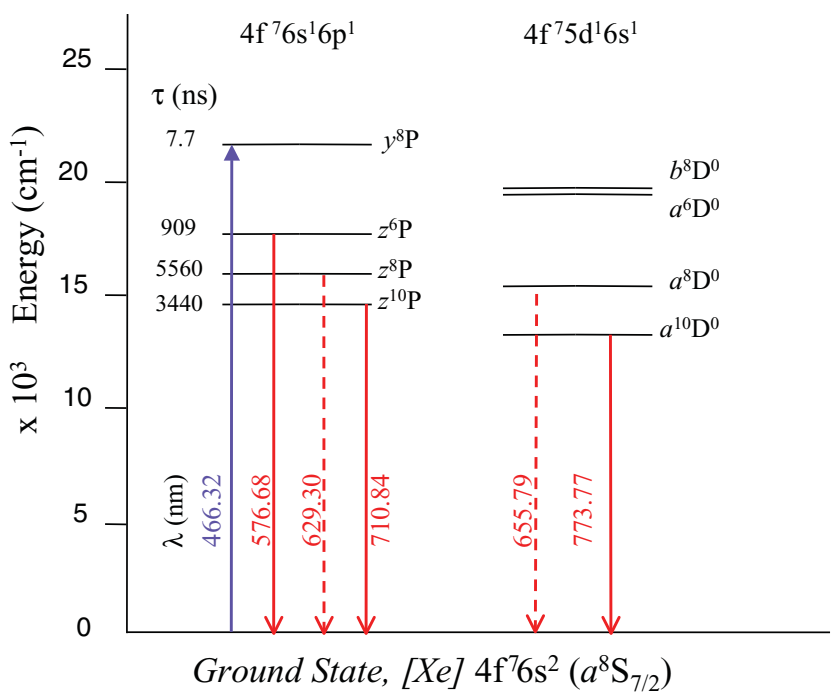

FIG. 1. An energy level diagram of gas phase atomic europium pertaining to states lower in energy than the $y^{8} \mathrm{P}_{5 / 2}$ state. All of the states involved are derived from just two configurations namely the $4 \mathrm{f}^{7} 6 \mathrm{~s}^{1} 6 \mathrm{p}^{1}$ and the $4 \mathrm{f}^{7} 5 \mathrm{~d}^{1} 6 \mathrm{~s}^{1}$. The $\mathrm{y}^{8} \mathrm{P} \leftarrow a^{8} \mathrm{~S}_{7 / 2}$ transition has the largest absorption oscillator strength occurring at $21444.6 \mathrm{~cm}^{-1}(466.3 \mathrm{~nm})$. States implicated in emission in Eu/RG matrices are indicated by the downward arrows.

iCCD camera or be diverted at right angles to the photon counting PMT.

A pulsed dye laser (Quantel TDL90) pumped by the second $(532 \mathrm{~nm})$ or third $(355 \mathrm{~nm})$ harmonics of a Nd:YAG laser (Quantel YG980E) was used as the excitation source for time-resolved measurements. The YAG laser was operated at a repetition rate of $10 \mathrm{~Hz}$ and the temporal profile of the pulse is about $4 \mathrm{~ns}$ fwhm. The following dyes were employed for the spectral ranges specified in brackets: Coumarin 440 [420-470 nm], Coumarin 460 [444-476 nm], Coumarin 480 [462-497 nm], and Rhodamine 6G [555-580 nm]. Typical laser outputs of $1-3 \mu \mathrm{J} / \mathrm{mm}^{2}$ were obtained using either the oscillator of the TDL90 on its own or with the preamplifier. Nanosecond decaytimes were extracted by taking "kinetic slices" at specific wavelengths from time-resolved emission spectra (TRES) recorded with the iCCD detector and controller card (CCI-010) mounted on a PC. Trial functions were fit to decay curves extracted at a specific emission wavelength by convoluting with the temporal profile of the laser excitation pulse. Longer-lived ( $\mu \mathrm{s}$, ms) decay times were measured using the photon counting technique and recorded with multi-channel scaling (MCS). The signal from the photon counting (R928-P) emission PMT was amplified by a fast-timing preamplifier (Ortec, model VT120) and to limit electronic noise, relayed to a constant-fraction discriminator (CFD) (Ortec, model 584). The output of the CFD was passed simultaneously to the stop-in on a $2 \mathrm{GHz}$ multi-channel scalar (Fast ComTec, Model 7886) and to a ratemeter (Ortec, model 661). Counting rates were monitored to avoid the occurrence of pulse-pile up in the recorded decay curves. The start trigger for the MCS unit was taken from the Q-switch pulse of the Nd:YAG laser. Lifetimes were extracted from the experimental data by fitting single or multiple exponential functions to the decay curves and performing a non-linear least squares fit analysis. The fits were generally performed over four orders of magnitude of decay in the emission intensity.

Once matrix radiative lifetimes $\left(\tau_{o b s}\right)$ were identified they were corrected with Eq. (1) for the effective field ${ }^{5,6}$ of the solid which accounts for the effect of the surrounding dielectric medium on the emitting guest,

$$
\tau_{c o r}=\tau_{o b s} n\left[s\left(n^{2}-1\right)+1\right]^{2} .
$$

The formula is a function of the index of refraction, $n$, of the given rare gas host and a "shape" parameter, $s$. This parameter is a depolarisation factor related to the symmetry of the site accommodating the guest atom. Applying this formula the corrected lifetime $\left(\tau_{c o r}\right)$ obtained can be compared with the vacuum lifetimes. For isotropic cavities, $s=1 / 3$ and Eq. (1) becomes the more recognisable formula,

$$
\tau_{c o r}=\tau_{o b s} n\left[\left(n^{2}+2\right) / 3\right]^{2} .
$$

Refractive indices of 1.32, 1.43, and 1.49 are used for $\mathrm{Ar}, \mathrm{Kr}$, and $\mathrm{Xe}$, respectively. ${ }^{7}$

\section{RESULTS AND ANALYSIS}

Overviews of the entire Eu/RG matrix emission produced with site selective $y^{8} \mathrm{P}$ state excitation of the blue and red bands in each of the RG's are provided by the spectra shown in Figs. 2 and 3 respectively. Four emission regions are observed for europium atoms isolated in both sites. The most intense emission is centred around $460 \mathrm{~nm}$. Weaker emission bands occur in both the 570 and $680 \mathrm{~nm}$ regions and the lowest energy features are identified in the $800 \mathrm{~nm}$ range. Details of the emission occurring in each of these spectral regions will now be analysed with the aim of obtaining transition assignments.

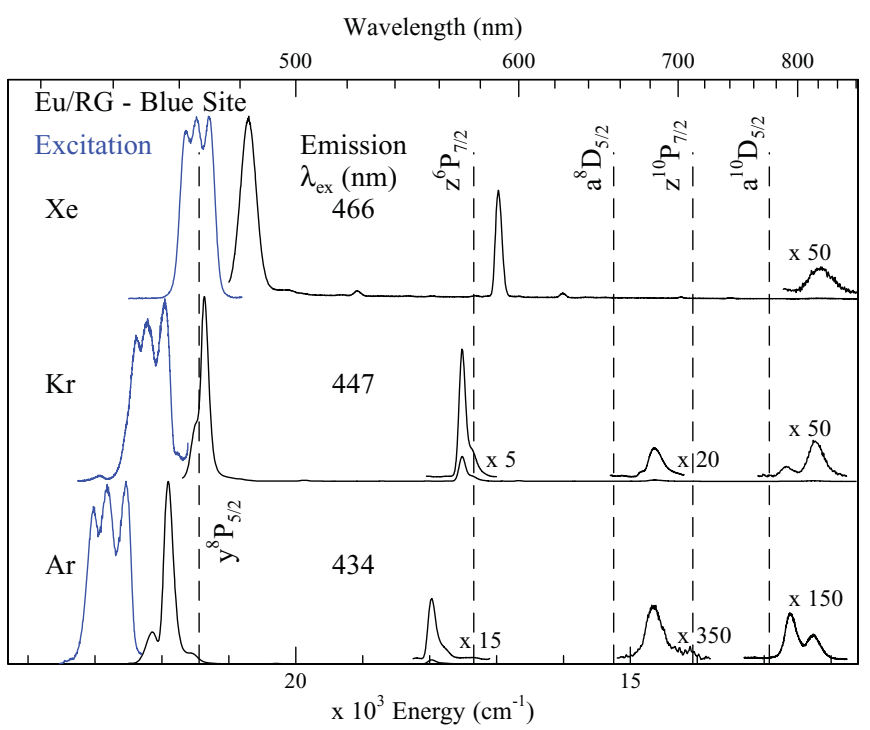

FIG. 2. Emission spectra recorded at $10 \mathrm{~K}$ for Eu/Ar, Eu/Kr and Eu/Xe systems with site-selective lamp excitation of the high energy blue site corresponding to the $\mathrm{Eu} y^{8} \mathrm{P} \leftarrow a^{8} \mathrm{~S}$ transition. The excitation wavelengths used are shown as $\lambda_{\text {ex }}(\mathrm{nm})$. The excitation spectra are shown to the left. All spectra were recorded at $10 \mathrm{~K}$ following deposition at $10 \mathrm{~K}$ and sample annealing to 26, 36, and $60 \mathrm{~K}$ for $\mathrm{Ar}, \mathrm{Kr}$ and $\mathrm{Xe}$ samples, respectively. The gas phase spectral positions of the assigned transitions of atomic Eu are shown by the dashed vertical lines. 


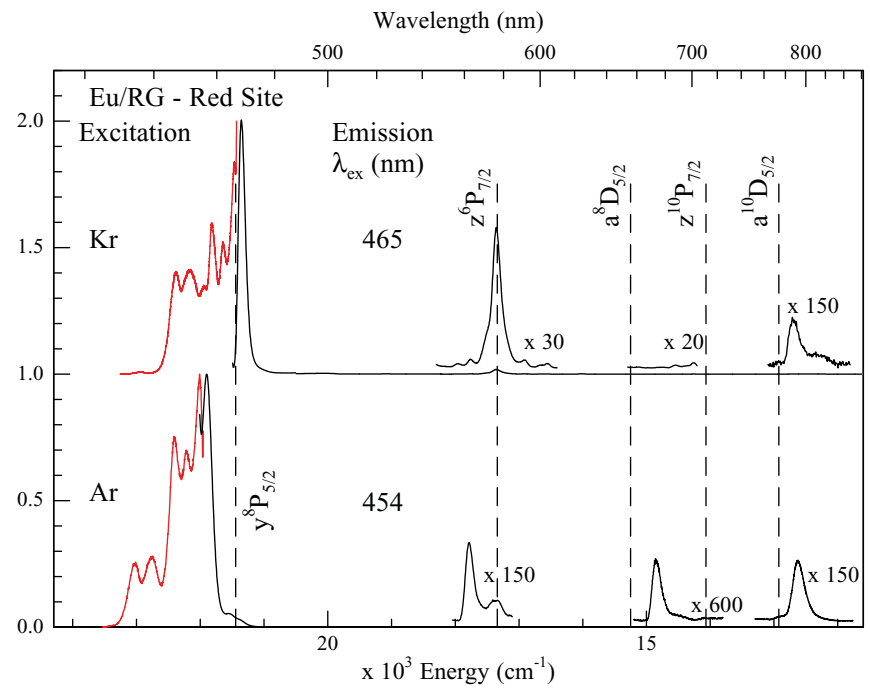

FIG. 3. Emission spectra recorded at $10 \mathrm{~K}$ for $\mathrm{Eu} / \mathrm{Ar}$ and $\mathrm{Eu} / \mathrm{Kr}$ systems with site-selective lamp excitation of the low energy red site corresponding to the $\mathrm{Eu} y^{8} \mathrm{P} \leftarrow a^{8} \mathrm{~S}_{5 / 2}$ transition. The red site is absent in Eu/Xe.

\section{A. $460 \mathrm{~nm}$ region}

A summary of the complex emission bandshapes present in the $460 \mathrm{~nm}$ region is shown in Fig. 4. Of the three rare gases studied, Eu/Xe is clearly the simplest system as it presents just a single site which in previous absorption work ${ }^{1}$, has been associated with the blue sites in $\mathrm{Ar}$ and $\mathrm{Kr}$. The form of the excitation/emission pair in $\mathrm{Eu} / \mathrm{Xe}$, shown in the top of Fig. 4, is typical of a $\mathrm{P} \leftrightarrow \mathrm{S}$ state transition ${ }^{8}$ for an atomic guest isolated in a site of high symmetry. Thus, a pronounced threefold splitting is evident in the excitation band, behaviour characteristic of the Jahn-Teller effect while the emission consists of a featureless band exhibiting a large Stokes shift. Emission decay curves of the $483 \mathrm{~nm}$ band were extracted from TRES recorded with the iCCD camera. The temperature dependence

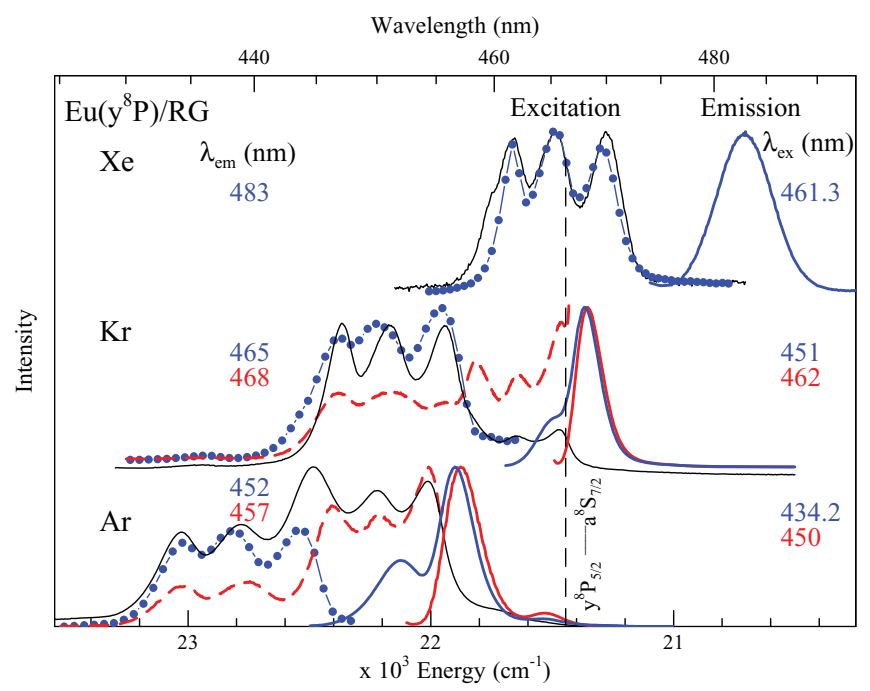

FIG. 4. Details of the site-specific excitation and emission spectra recorded for the three $\mathrm{Eu} / \mathrm{RG}$ systems in the $460 \mathrm{~nm}$ spectral region with $y^{8} \mathrm{P}$ state excitation. The spectral position of the gas phase $y^{8} \mathrm{P} \leftarrow a^{8} \mathrm{~S}_{5 / 2}$ transition of atomic Eu is shown by the dashed vertical line. The matrix absorption spectra are shown by the solid black trace.

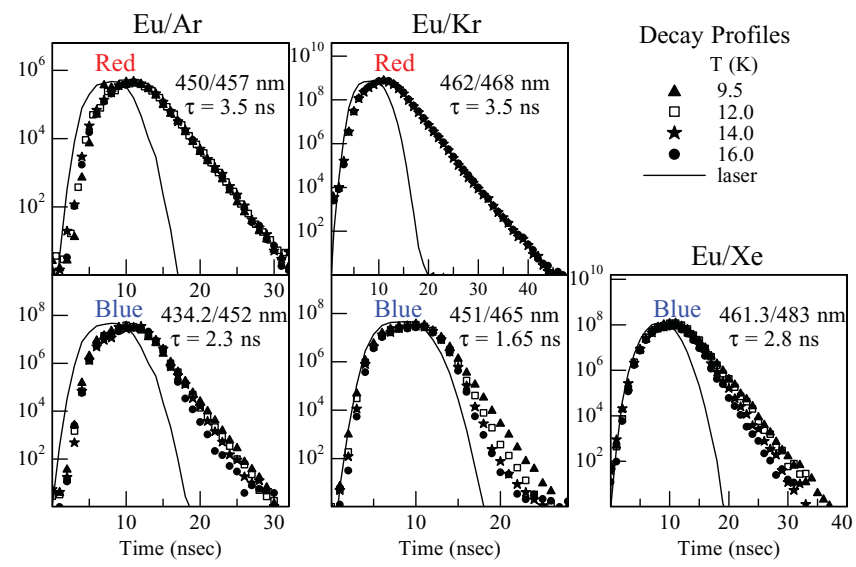

FIG. 5. Emission decay profiles recorded for the three annealed Eu/RG systems produced with the specified excitation/emission wavelengths. Striking in this plot is the temperature independence exhibited by the red site and the strong dependence exhibited by the blue site.

of this data is presented on the bottom right in Fig. 5. Even with a small increase in temperature from 9.5 to $16 \mathrm{~K}$, the decay time is observed to shorten. As a result, the $2.8 \mathrm{~ns}$ value recorded at $9.5 \mathrm{~K}$, the lowest temperature achievable with our current cryostat, cannot be identified as the radiative lifetime. The photophysical characteristics of this and the other $\mathrm{Eu} / \mathrm{Xe}$ emission bands are collected on the bottom of Table I. In contrast to $\mathrm{Xe}$, the emission produced with excitation of the corresponding blue sites in Ar and $\mathrm{Kr}$ produce complex bandshapes due to re-absorption by the red site. Since this latter site is comparatively straightforward, red site emission data will be presented first.

\section{Red site}

As shown in Fig. 4, emission from the red site in solid Ar is centred at $457.3 \mathrm{~nm}\left(21867 \mathrm{~cm}^{-1}\right)$ and $468.3 \mathrm{~nm}$ $\left(21352 \mathrm{~cm}^{-1}\right)$ in $\mathrm{Kr}$. The excitation spectrum recorded monitoring the $457 \mathrm{~nm}$ emission feature is presented as the dashed line in the lower panel of Figure 4. A Stokes shift of $350 \mathrm{~cm}^{-1}$, determined from the central excitation component at $450.1 \mathrm{~nm}(462.0 \mathrm{~nm}, \mathrm{Kr})$ to the emission maximum is calculated, while its value is $292 \mathrm{~cm}^{-1}$ in $\mathrm{Kr}$. The temporal characteristics of these emission features were successfully fit with single exponential functions having lifetimes of $3.5 \mathrm{~ns}$ in both $\mathrm{Ar}$ and $\mathrm{Kr}$ matrices. As shown in the upper section of Fig. 5, the emission decay profiles recorded in the 9.5 to $16 \mathrm{~K}$ range displayed no temperature dependence in either system indicating the radiative lifetimes have been recorded for this site. When the $3.5 \mathrm{~ns}$ value is corrected by Eq. (2) for the effective field of the surrounding Ar lattice, the matrix radiative lifetime becomes $7.2 \mathrm{~ns}$ which compares very favourably to the gas phase ${ }^{2}$ value of $7.7 \mathrm{~ns}$ for the $y^{8} \mathrm{P}_{5 / 2} \leftrightarrow a^{8} \mathrm{~S}_{7 / 2}$ transition. The corrected lifetime in solid $\mathrm{Kr}$ is of similar magnitude at $9.1 \mathrm{~ns}$. Since the gas phase transition ${ }^{2}$ occurs at $466.32 \mathrm{~nm}$ $\left(21444.58 \mathrm{~cm}^{-1}\right)$, the matrix emission bands exhibit shifts of $+422 \mathrm{~cm}^{-1}$ and $-92 \mathrm{~cm}^{-1}$ in Ar and $\mathrm{Kr}$, respectively. 
TABLE I. Photophysical characteristics of the emission features of the Red and Blue sites of isolation in Eu/RG revealed in the luminescence study of the $y^{8} \mathrm{P}\left(4 \mathrm{f}^{7} 6 \mathrm{~s}^{1} 6 \mathrm{p}^{1}\right)$ state of atomic Eu. The spectral position is quoted in $\lambda(\mathrm{nm})$ and $v\left(\mathrm{~cm}^{-1}\right)$. The bandwidth (fwhm) is denoted as $\Delta$. Gas phase to matrix frequency shifts for the assigned atomic Eu transition, $\delta$, are displayed in wavenumber units. The observed lifetimes recorded in the matrix at $10 \mathrm{~K}$ are labelled $\tau_{10 \mathrm{~K}}$.

\begin{tabular}{|c|c|c|c|c|c|}
\hline State & $v\left(\mathrm{~cm}^{-1}\right)$ & $\lambda(\mathrm{nm})$ & $\Delta\left(\mathrm{cm}^{-1}\right)$ & $\delta\left(\mathrm{cm}^{-1}\right)$ & $\tau_{10 \mathrm{~K}}$ \\
\hline \multicolumn{6}{|c|}{ Eu gas phase } \\
\hline$y^{8} \mathrm{P}_{5 / 2}$ & 21444.58 & 466.3 & $\ldots$ & $\ldots$ & $7.7 \mathrm{~ns}$ \\
\hline$z^{6} \mathrm{P}_{7 / 2}$ & 17340.65 & 576.68 & $\ldots$ & $\ldots$ & $909.1 \mathrm{~ns}$ \\
\hline$a^{8} \mathrm{D}_{5 / 2}$ & 15248.76 & 655.78 & $\ldots$ & $\ldots$ & $\ldots$ \\
\hline$z^{10} \mathrm{P}_{7 / 2}$ & 14067.86 & 710.84 & $\ldots$ & $\ldots$ & $3440 \mathrm{~ns}$ \\
\hline$a^{10} \mathrm{D}_{5 / 2}$ & 12923.7 & 773.77 & $\ldots$ & $\ldots$ & $\ldots$ \\
\hline \multicolumn{6}{|c|}{$\mathrm{Eu} / \mathrm{Ar} \operatorname{red}\left(1^{0}\right)$ site } \\
\hline$y^{8} \mathrm{P}_{5 / 2}$ & 21867 & 457.3 & 167 & +422 & $3.5 \mathrm{~ns}$ \\
\hline$z^{6} \mathrm{P}_{7 / 2}$ & 17767 & 562.9 & 144 & +427 & $72,280 \mathrm{~ns}$ \\
\hline$a^{8} \mathrm{D} / z^{10} \mathrm{P}$ & 14815 & 675 & 274 & $-434 /+747$ & $4,32,353 \mu \mathrm{s}$ \\
\hline$a^{10} \mathrm{D}_{5 / 2}$ & 12649 & 790.6 & 203 & -275 & $0.69,2.12 \mathrm{~ms}$ \\
\hline \multicolumn{6}{|c|}{$\mathrm{Eu} / \mathrm{Ar}$ blue $\left(2^{\circ}\right)$ site } \\
\hline$y^{8} \mathrm{P}_{5 / 2}$ & 22141 & 451.6 & 192 & +697 & $2.3 \mathrm{~ns}$ \\
\hline$z^{6} \mathrm{P}_{7 / 2}$ & 17954 & 557 & 125 & +614 & $33,240 \mathrm{~ns}$ \\
\hline$a^{8} \mathrm{D} / z^{10} \mathrm{P}$ & 14650 & 682.6 & 285 & $-599 /+582$ & $8,51,174 \mu \mathrm{s}$ \\
\hline$a^{10} \mathrm{D}_{5 / 2}$ & 12281 & 814.3 & 281 & -643 & $0.41,1.34 \mathrm{~ms}$ \\
\hline \multicolumn{6}{|c|}{$\mathrm{Eu} / \mathrm{Kr}$ red $\left(2^{\circ}\right)$ site } \\
\hline$y^{8} \mathrm{P}_{5 / 2}$ & 21352 & 468.3 & 127 & -92 & $3.5 \mathrm{~ns}$ \\
\hline$z^{6} \mathrm{P}_{7 / 2}$ & 17351 & 576.3 & 176 & +10 & $30,140,370 \mathrm{~ns}$ \\
\hline$a^{10} \mathrm{D}_{5 / 2}$ & 12671 & 789.2 & 217 & -253 & $0.8,2.2 \mathrm{~ms}$ \\
\hline \multicolumn{6}{|c|}{$\mathrm{Eu} / \mathrm{Kr}$ blue $\left(1^{\circ}\right)$ site } \\
\hline$y^{8} \mathrm{P}_{5 / 2}$ & 21523 & 464.6 & 108 & +78 & $1.65 \mathrm{~ns}$ \\
\hline$z^{6} \mathrm{P}_{7 / 2}$ & 17515 & 570.9 & 103 & +174 & $36,125 \mathrm{~ns}$ \\
\hline$a^{8} \mathrm{D} / z^{10} \mathrm{P}$ & 14641 & 683 & 236 & $-608 /+573$ & $1.6,8.8,62.1 \mu \mathrm{s}$ \\
\hline$a^{10} \mathrm{D}_{5 / 2}$ & 12262 & 815.5 & 285 & -662 & $0.8,2.4 \mathrm{~ms}$ \\
\hline \multicolumn{6}{|c|}{$\mathrm{Eu} / \mathrm{Xe}$} \\
\hline$y^{8} \mathrm{P}_{5 / 2}$ & 20707 & 483 & 268 & -737 & $2.8 \mathrm{~ns}$ \\
\hline$z^{6} \mathrm{P}_{7 / 2}$ & 16969 & 589.3 & 110 & -372 & $4,30,95 \mathrm{~ns}$ \\
\hline$a^{10} \mathrm{D}_{5 / 2}$ & 12145 & 823.4 & 367 & -779 & $1.2 \mathrm{~ms}$ \\
\hline
\end{tabular}

\section{Blue site}

Blue site $y^{8} \mathrm{P}$ state excitation in $\mathrm{Ar}$ and $\mathrm{Kr}$ produces two emission features centred at 452 (B) and 457 (R) $\mathrm{nm}$ in $\mathrm{Ar}$ and $465(\mathrm{~B})$ and $468(\mathrm{R}) \mathrm{nm}$ in $\mathrm{Kr}$ as shown in Fig. 4. Thus, red site emission in Ar at $457 \mathrm{~nm}(468 \mathrm{~nm} \mathrm{Kr})$ is produced with blue site excitation. This occurs due to the re-absorption arising from the spectral overlap between the blue site emission and the red site absorption. It can be seen most clearly for the Ar data ${ }^{9}$ presented in bottom left panel in Fig. 4 in which re-absorption of the blue site emission centred at $452 \mathrm{~nm}$ occurs from the red site absorption feature centred at $450.1 \mathrm{~nm}$, which subsequently emits at $457.3 \mathrm{~nm}$.

Taking this phenomenon into account, the true blue site emissions are located at 452, 465, and $483 \mathrm{~nm}$ in $\mathrm{Ar}$, $\mathrm{Kr}$, and Xe, respectively, exhibiting Stokes shifts of 674, 657, and 769 $\mathrm{cm}^{-1}$. Decaytimes of $2.3(\mathrm{Ar}), 1.65(\mathrm{Kr})$, and $2.8(\mathrm{Xe}) \mathrm{ns}$ are recorded at $9.5 \mathrm{~K}$ all of which are shorter than the $3.5 \mathrm{~ns}$ lifetime of the red site fluorescence. As is illustrated in the lower panel of Fig. 5, blue site emission decay curves recorded from
9.5 to $16 \mathrm{~K}$ exhibit considerable temperature dependence in each host. This effect was observed to be completely reversible and is in stark contrast to the red site emission (shown directly above), which doesn't change in the same temperature range. Consequently, the radiative lifetime of the blue site emission has not been identified in any of the three host solids. However, due to their spectral location and short-lived decay time, these emission features are also assigned as resonance fluorescence from the $y^{8} \mathrm{P}$ excited state. While the blue site emission bandshapes are corrupted by re-absorption, their excitation scans provide the true spectral shape of the blue site free from overlap with the red site as occurs for the absorption spectrum shown by the solid black trace of Fig. 4 .

\section{B. $570 \mathrm{~nm}$ region}

The Eu/RG emission features with the next greatest intensity are, as is evident in Figs. 2 and 3, located in the 560$580 \mathrm{~nm}$ spectral region.

\section{Red site}

Emission from the red site occurs at 563 and $571 \mathrm{~nm}$ for $\mathrm{Ar}$ and $\mathrm{Kr}$, respectively. As shown in top right panel of Figure 6, the temporal profile of the Eu/Ar $563 \mathrm{~nm}$ emission (recorded at $9.5 \mathrm{~K}$ ) was fit with a double exponential function yielding decay times of 72 and $280 \mathrm{~ns}$ with amplitudes of 1450 and 1050, respectively. In solid $\mathrm{Kr}$, a triple exponential function having decay times of 30, 140 and $370 \mathrm{~ns}$ and amplitudes of 830,680 , and 470 , respectively, were required to fit the $9.5 \mathrm{~K}$ data. The emission decay curves are temperature independent in the range 9.5 to $16 \mathrm{~K}$, indicating the radiative lifetime has been identified in each host. When corrected for

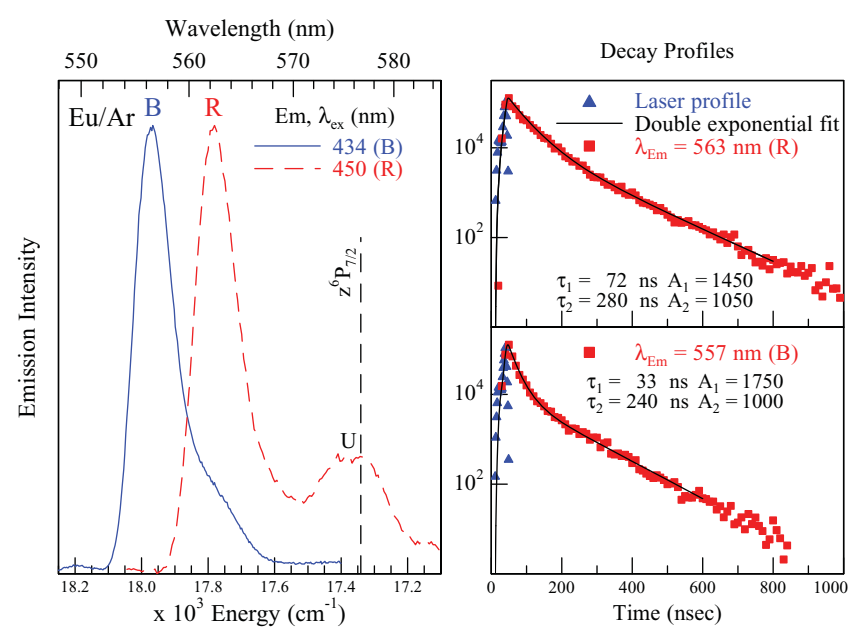

FIG. 6. Left panel, emission spectra produced in the $560 \mathrm{~nm}$ spectral region with site-specific $y^{8} \mathrm{P}$ state excitation of Eu/Ar at $10 \mathrm{~K}$ following deposition at $10 \mathrm{~K}$ and sample annealing to $30 \mathrm{~K}$. A minor amount of thermally unstable site emission (U) is observed due to some residual atoms remaining in this site. The gas phase position of the nearest $\mathrm{P} \rightarrow \mathrm{S}$ type electronic transition of atomic Eu, $z^{6} \mathrm{P}_{7 / 2}$, is shown by the dashed vertical line. In the right panel, decay profiles of the Eu/Ar emission at 557 and $563 \mathrm{~nm}$ recorded at $10 \mathrm{~K}$ in an annealed sample are shown. The decay profile is convoluted with the temporal profile of the laser excitation source. The recorded decay is fit with a double exponential. 
the effective field of the surrounding matrix, lifetime values of 147 and $575 \mathrm{~ns}$ (Ar) and 78, 362, and $958 \mathrm{~ns}(\mathrm{Kr})$ are obtained. The short $(<\mu \mathrm{s})$ lifetime of these features suggest they result from a partly allowed electric-dipole transition, i.e., a parity allowed but spin forbidden $\mathrm{P} \rightarrow \mathrm{S}$ transition. Inspection of the energy level diagram for atomic Eu shown in Fig. 1 indicates there are three $\mathrm{P}$ states at lower energy than the $y^{8} \mathrm{P}$ electronic state, namely the $z^{6} \mathrm{P}, z^{8} \mathrm{P}$, and $z^{10} \mathrm{P}$ states, whose transitions to the ground state occur at 576.7, 629.3, and $710.8 \mathrm{~nm}$, respectively, in the gas phase. The nearest transition is therefore the $z^{6} \mathrm{P}_{7 / 2} \rightarrow a^{8} \mathrm{~S}_{7 / 2}$ at $576.7 \mathrm{~nm}$ suggesting the observed emission is due to the $z^{6} \mathrm{P}$ state. This assignment is further supported when the gas phase lifetimes of the possible $\mathrm{P} \rightarrow \mathrm{S}$ type electronic transitions are considered. Thus, as indicated in Table II, the $z^{6} \mathrm{P}_{7 / 2} \rightarrow a^{8} \mathrm{~S}_{7 / 2}$ transition has a lifetime of several hundred nanoseconds which compares favourably to the longer components (hundreds of ns) values recorded for the $563(\mathrm{Ar})$ and $571(\mathrm{Kr}) \mathrm{nm}$ emissions.

\section{Blue site}

The corresponding blue site emissions are observed at $557(\mathrm{Ar}), 576(\mathrm{Kr})$ and $589(\mathrm{Xe}) \mathrm{nm}$ with, as illustrated in Fig. 2, the $589 \mathrm{~nm}$ band in Xe almost as intense as the $460 \mathrm{~nm}$ band. An emission decay curve consisting of two components $\tau_{1}=33$ and $\tau_{2}=240 \mathrm{~ns}$ was recorded in Eu/Ar at $9.5 \mathrm{~K}$ (bottom right panel of Figure 6). The shorter (33 ns) component is unchanged in the temperature range 9.5 to $16 \mathrm{~K}$. However, the longer component shows a gradual shortening at increased temperatures. Fits of the decay profile in solid $\mathrm{Kr}$ also required double exponentials, consisting of two components, $\tau_{1}=36$ and $\tau_{2}=125 \mathrm{~ns}$ with amplitudes of 2800 and 1400 , respectively. The lifetimes do not change in the temperature range up to $23 \mathrm{~K}$ indicating the radiative lifetime of this transition has been observed. In solid Xe, the $589 \mathrm{~nm}$ temporal profile consists of a triple exponential with lifetimes of $\tau_{1}$ $=4, \tau_{2}=30$ and $\tau_{3}=95 \mathrm{~ns}$ and amplitudes of 800, 1000, and 750 , respectively. An analysis of the effects of varying temperature reveals there is no change in any of the three lifetime components up to $16 \mathrm{~K}$. Above this temperature the longest (95 ns) lifetime component begins to shorten.

TABLE II. Temporal and spectral characteristics of the $\mathrm{P}\left(4 \mathrm{f}^{7} 6 \mathrm{~s}^{1} 6 \mathrm{p}^{1}\right)$ $\leftrightarrow a^{8} \mathrm{~S}\left(4 \mathrm{f}^{7} 6 \mathrm{~s}^{2}\right)$ type electronic transitions of atomic europium occurring at $\lambda>500 \mathrm{~nm}$ in the gas phase. The lifetimes quoted are from various sources; their year of publication is displayed in brackets. The most recent data available is Ref. 15 from 2002.

\begin{tabular}{lllll}
\hline \hline & \multicolumn{4}{c}{ Gas Phase $\mathrm{P} \rightarrow \mathrm{S}$ type transitions $>500 \mathrm{~nm}$} \\
\cline { 2 - 5 } Transition & $\lambda(\mathrm{nm})$ & $\tau(2002)$ & $\tau(1984)^{\mathrm{a}}$ & $\tau(1975)$ \\
\hline$z^{6} \mathrm{P}_{5 / 2} \leftrightarrow a^{8} \mathrm{~S}_{7 / 2}$ & 564.5 & $1.38 \mu \mathrm{s}$ & $1.28 \mu \mathrm{s}$ & $1.85 \mu \mathrm{s}$ \\
$z^{6} \mathrm{P}_{7 / 2} \leftrightarrow a^{8} \mathrm{~S}_{7 / 2}$ & 576.5 & $870 \mathrm{~ns}$ & $858 \mathrm{~ns}$ & $909 \mathrm{~ns}$ \\
$z^{8} \mathrm{P}_{9 / 2} \leftrightarrow a^{8} \mathrm{~S}_{7 / 2}$ & 601.8 & $1.05 \mu \mathrm{s}$ & $1.06 \mu \mathrm{s}$ & $1.18 \mu \mathrm{s}$ \\
$z^{8} \mathrm{P}_{7 / 2} \leftrightarrow a^{8} \mathrm{~S}_{7 / 2}$ & 626.7 & $\ldots$ & $14.9 \mu \mathrm{s}$ & $\ldots$ \\
$z^{8} \mathrm{P}_{5 / 2} \leftrightarrow a^{8} \mathrm{~S}_{7 / 2}$ & 629.1 & $\ldots$ & $4.92 \mu \mathrm{s}$ & $5.56 \mu \mathrm{s}$ \\
$z^{10} \mathrm{P}_{9 / 2} \leftrightarrow a^{8} \mathrm{~S}_{7 / 2}$ & 686.5 & $\ldots$ & $1.25 \mu \mathrm{s}$ & $1.72 \mu \mathrm{s}$ \\
$z^{10} \mathrm{P}_{7 / 2} \leftrightarrow a^{8} \mathrm{~S}_{7 / 2}$ & 710.6 & $\ldots$ & $3.44 \mu \mathrm{s}$ & $3.85 \mu \mathrm{s}$ \\
\hline \hline${ }^{a}$ Reference 16. & \multicolumn{5}{l}{}
\end{tabular}

${ }^{a}$ Reference 16.

\section{C. $570 \mathrm{~nm}$ emission produced with direct excitation}

In an effort to further investigate the kinetics of the $z^{6} \mathrm{P}$ state matrix emission, direct $z^{6} \mathrm{P} \leftarrow a^{8}$ S excitation was undertaken with laser radiation to provide the simplest relaxation pathway possible for this state. Excitation spectra recorded in this region have been presented previously in Paper I for the blue site and are now displayed in Fig. 7 along with the resulting emission. In Ar, excitation of the two resolved bands at 541 and $552.7 \mathrm{~nm}$ (shown on the bottom of Fig. 7) yields identical emission centred at $557 \mathrm{~nm}$. The temporal profile of this emission feature produced with excitation at $552.7 \mathrm{~nm}$ exhibits a double exponential decay with values of 30 and $96 \mathrm{~ns}$ at $10 \mathrm{~K}$. Excitation at 554.2 and $567 \mathrm{~nm}$ in $\mathrm{Kr}$ also produces identical emission bands centred at $576 \mathrm{~nm}$. The temporal profile of the $576 \mathrm{~nm}$ feature recorded with excitation at $566 \mathrm{~nm}$ at $13 \mathrm{~K}$ exhibits a double exponential decay yielding lifetimes of 38 and $107 \mathrm{~ns}$. These lifetimes are very similar to those recorded with indirect $y^{8} \mathrm{P}$ state excitation (36 and $125 \mathrm{~ns}$ ). Temporal profiles recorded at elevated temperatures with $z^{6} \mathrm{P}$ state excitation show little variation in the 13 to $23 \mathrm{~K}$ range yielding matrix corrected lifetime components of 98 and 277 ns.

Photo-excitation of the structured bands in the excitation spectrum of Eu/Xe produced identical emission centred at $589 \mathrm{~nm}$. The temporal profile of this emission feature recorded with excitation at $568.3 \mathrm{~nm}$ exhibits a double exponential decay with lifetime components of 37 and $88 \mathrm{~ns}$ at $12.8 \mathrm{~K}$. These values are of the same magnitude (30 and $95 \mathrm{~ns}$ ) as those obtained with indirect $y^{8} \mathrm{P}$ state excitation. The decay profile produced with $z^{6} \mathrm{P}$ state excitation and recorded at increased temperatures exhibited no thermal dependence in the range 12.8 to $15 \mathrm{~K}$. Accordingly, the radiative lifetime is identified and when corrected for the effective field of the host, values of 109 and $260 \mathrm{~ns}$ are obtained.

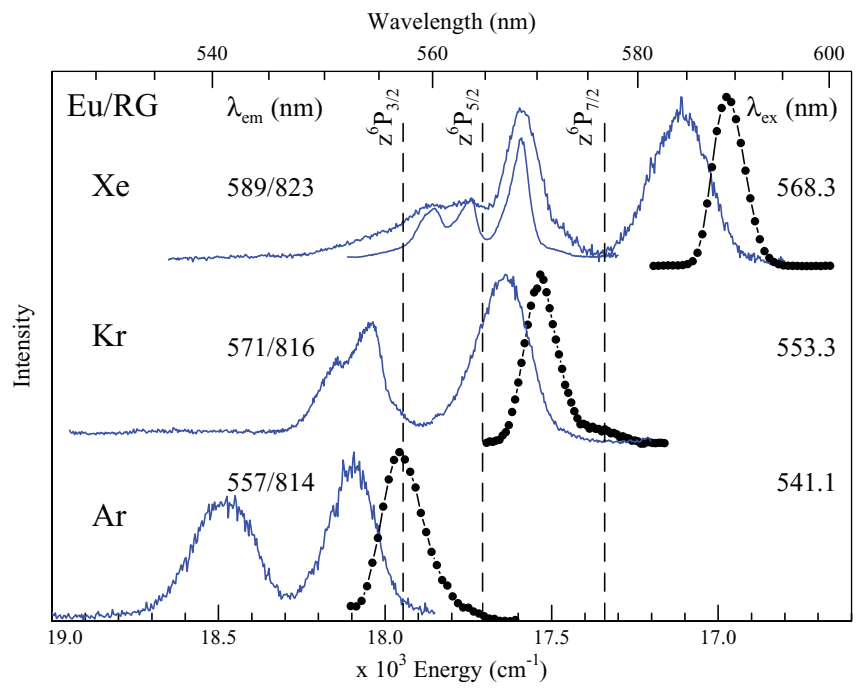

FIG. 7. Eu/RG blue site excitation spectra (solid trace) recorded in the region of the $z^{6} \mathrm{P}$ state of atomic Eu are shown together with the resulting emission bands (dotted trace). The emission wavelengths used to record the excitation spectra are indicated as the $\lambda_{\mathrm{em}}$ values. The spectral positions of each of the three $z^{6} \mathrm{P}$ spin-orbit levels in the gas phase are shown by the dashed vertical lines. 
In all three rare gases the temporal profiles of the $z^{6} \mathrm{P}$ state emission feature produced with direct $z^{6} \mathrm{P}$ excitation and indirect $y^{8} \mathrm{P}$ excitation yielded approximately the same lifetimes implying the non-radiative feeding step from the upper $y^{8} \mathrm{P}$ state, caused by a crossing of the $y^{8} \mathrm{P}$ and $z^{6} \mathrm{P}$ potentials, is rapid and cannot be detected on the nanosecond timescale used here. However, both excitations produce complex, multicomponent decays in the three systems, the origin of which is not immediately evident from the recorded emission bandshapes.

\section{D. $680 \mathrm{~nm}$ region}

The emission bands present in the $680 \mathrm{~nm}$ spectral region are the weakest observed. Indeed no emission is present in this region for $\mathrm{Eu} / \mathrm{Xe}$ and in $\mathrm{Eu} / \mathrm{Kr}$, only the blue site emits. In contrast, both sites are observed in this region for Eu/Ar.

\section{Red site}

Emission from the red site is observed only in solid Ar, it is centred at $675 \mathrm{~nm}\left(14815 \mathrm{~cm}^{-1}\right)$ and exhibits a broad bandwidth of $274 \mathrm{~cm}^{-1}$. The decay profile yields a triple exponential at $9.5 \mathrm{~K}$ with lifetime components of 4,32 , and $353 \mu \mathrm{s}$ and amplitudes of 2030, 554, and 72, respectively, as shown on the upper right panel of Fig. 8.

\section{Blue site}

The corresponding emission from the blue site is centred at 682.6 and $683 \mathrm{~nm}$ in $\mathrm{Ar}$ and $\mathrm{Kr}$, respectively, with broad bandwidths of 285 and $236 \mathrm{~cm}^{-1}$. Fitting the temporal profiles at $9.5 \mathrm{~K}$ again required a triple exponential with decay components of 8, 51, and $174 \mu \mathrm{s}$ in $\operatorname{Ar}$ (bottom right of Fig. 8) and 1.6, 8.8, and $62.1 \mu$ s in $\mathrm{Kr}$ with amplitudes of 1453, 1012, and 611, respectively. All the matrix emission bands observed

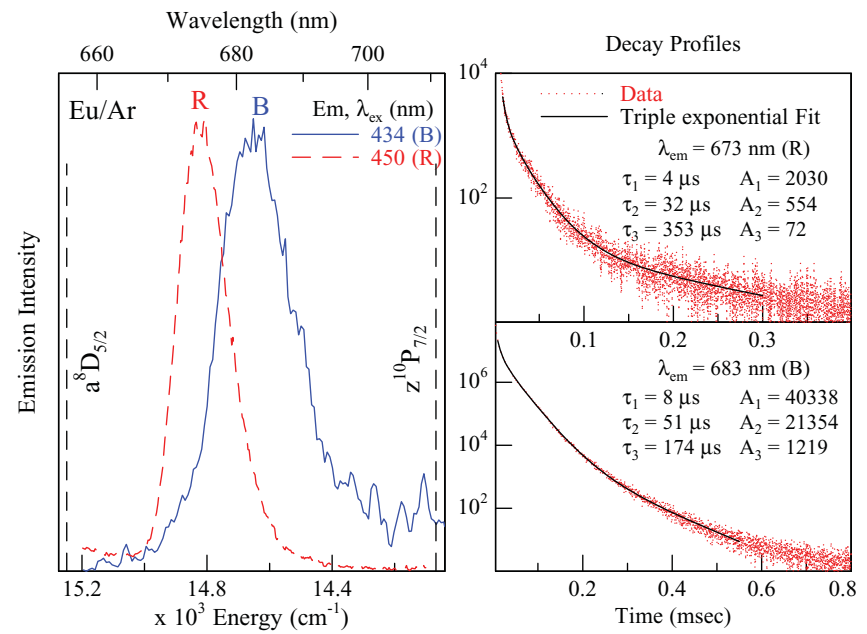

FIG. 8. Emission spectra produced in the $680 \mathrm{~nm}$ spectral region with sitespecific $y^{8} \mathrm{P}$ state excitation of Eu/Ar. The spectral positions of the nearest gas phase transitions of atomic Eu, the $a^{8} \mathrm{D}_{5 / 2}$ and the $z^{10} \mathrm{P}$ states are indicated by the dashed vertical lines. Decay profiles of the 673 and $683 \mathrm{~nm}$ emission recorded at $10 \mathrm{~K}$ using the Single Photon Counting technique with site specific $y^{8} \mathrm{P}$ state excitation are presented in right panel. in the $680 \mathrm{~nm}$ region are long-lived, but the dominant, short component is quite similar to the 3.44 (1.06) $\mu$ s lifetime of the $z^{10} \mathrm{P}_{7 / 2(9 / 2)} \rightarrow a^{8} \mathrm{~S}_{7 / 2}$ transition occurring at $710.8(686.6) \mathrm{nm}$ in the gas phase. However, the reversal of the spectral locations of the blue and red emission bands, as evidenced by the comparison shown for the Eu/Ar data shown in Fig. 8, suggests that the $680 \mathrm{~nm}$ bands corresponds to a $\mathrm{D} \rightarrow \mathrm{S}$ transition (see $800 \mathrm{~nm}$ region later). The nearest such transition in the gas phase is the $a^{8} \mathrm{D}_{5 / 2} \rightarrow a^{8} \mathrm{~S}_{7 / 2}$ occurring at $655.8 \mathrm{~nm}$. However, as no lifetime data are available for this transition in the gas phase, the assignment of this band requires further discussion which will be presented later.

\section{E. $800 \mathrm{~nm}$ region}

\section{Red site}

Emission in this region is observed at 791 (Ar) and $789(\mathrm{Kr}) \mathrm{nm}$. To aid in the identification of the excited state responsible for these emissions, their decay profiles were recorded and are displayed for Ar in Fig. 9. Long-lived, double exponential decays were identified in each host with lifetime components of 0.69 and $2.12 \mathrm{~ms}$ in Ar and 0.82 and $2.16 \mathrm{~ms}$ in $\mathrm{Kr}$. The decay profile is completely temperature independent in $\mathrm{Ar}(\mathrm{Kr})$ up to 27 (16) K ; thus, the radiative lifetime of these emissions are identified in the solids.

\section{Blue site}

Blue site emission features are centered at $814(\mathrm{Ar})$, $816(\mathrm{Kr})$, and $823(\mathrm{Xe}) \mathrm{nm}$. Figure 9 presents the decay profile recorded in Ar overlapped with a double exponential fit yielding two lifetime components of 0.41 and $1.34 \mathrm{~ms}$. Analysis of the temporal profile in $\mathrm{Kr}$ also reveals two decay components having lifetimes of 0.83 and $2.42 \mathrm{~ms}$ with amplitudes of 11208 and 2073, respectively. In Xe only a single exponential with a lifetime of $1.22 \mathrm{~ms}$ was required to fit the decay profile.

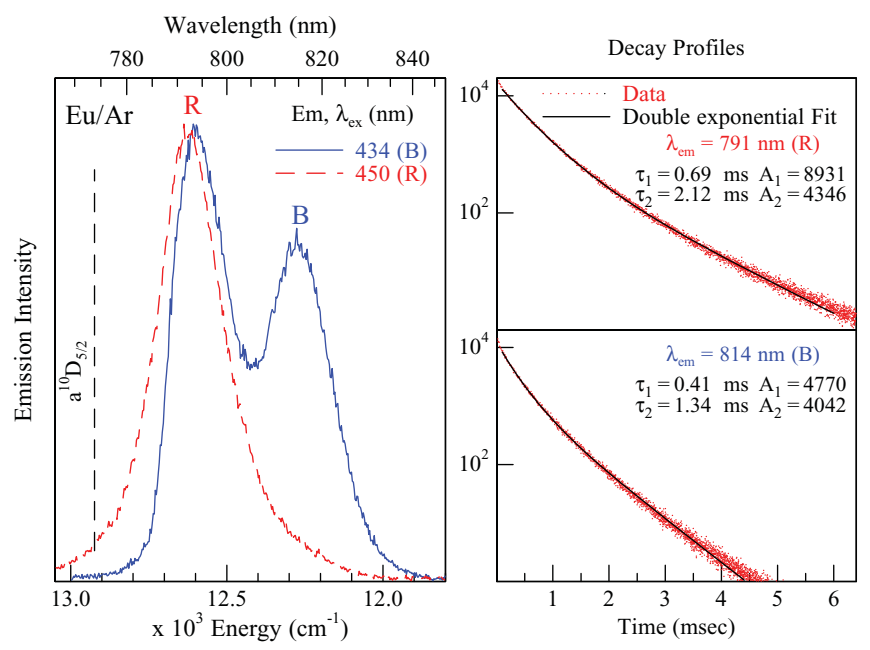

FIG. 9. Left panel, emission in the $800 \mathrm{~nm}$ spectral region produced with site-specific $y^{8} \mathrm{P}$ state excitation of Eu/Ar samples and recorded at $10 \mathrm{~K}$. The spectral position of the nearest gas phase transition of atomic $\mathrm{Eu}, a^{10} \mathrm{D}_{5 / 2}$, is indicated by the dashed vertical line. The temporal profiles of the 790 and 814 $\mathrm{nm}$ emission recorded with site-selective excitation are shown on the right. 
The photophysical characteristics of the bands in the $800 \mathrm{~nm}$ region are listed in Table I. Notably, the blue site is observed to emit to lower energy than the red site.

The very long-lived (millisecond) nature of the emission features in the $800 \mathrm{~nm}$ region is characteristic of an electric-dipole forbidden transition, such as a $\mathrm{D} \rightarrow \mathrm{S}$ transition. The nearest in the gas phase is the metastable $a^{10} \mathrm{D}_{5 / 2}$ $\leftrightarrow a^{8} \mathrm{~S}_{7 / 2}$ transition occurring at $773.77 \mathrm{~nm}\left(12923.72 \mathrm{~cm}^{-1}\right)$. A progressive increase in emission intensity is observed at higher temperatures for this band supporting the $a^{10} \mathrm{D}$ state assignment as it reveals that the lowest energy excited state is acting as a "population trap." The observed temporal and spectral characteristics of the $800 \mathrm{~nm}$ region features allow their assignment to the spin and parity forbidden $a^{10} \mathrm{D} \rightarrow a^{8} \mathrm{~S}$ transition of atomic Eu.

\section{DISCUSSION}

\section{A. Complex emission decay kinetics}

With the exception of the $y^{8} \mathrm{P}$ state fluorescence, all the other emission bands recorded in this study exhibit complex, multi-exponential decays most of which are, from their lack of temperature dependence, identified as radiative lifetimes. From the spectra recorded it is not immediately evident what the origin of this complex behaviour is. A possible reason which must be considered is the existence of multiple sites. However, the excitation conducted in this study is siteselective so the manifestation of such an effect should only produce secondary emission components having minor amplitudes. It will be recalled that most of the additional components have intensities nearly equal in magnitude to the major one. In addition, $\mathrm{Eu} / \mathrm{Xe}$ exhibits the same multi-component decay even though it contains only a single site type. For these reasons, the multiple site occupancy explanation can be excluded.

An indication of the possible origin of the complex behaviour is to be found in the $z^{6} \mathrm{P}$ state, which is known from Paper I to absorb as the pure $\mathrm{J}=7 / 2$ spin-orbit level. This behaviour - the existence of a distinct spin-orbit level - leads to considerable overlap between the excitation and emission spectra as is evident in Fig. 7. Its relevance to the complex emission decays is that the $\mathrm{J}=7 / 2$ level is split by a field of cubic symmetry (valid for either a tv or hv site) into three components $\left(G, E_{1}\right.$, and $\left.E_{2}\right)$ with intensity ratios $2 / 1 / 1$. This splitting is not evident on the $570 \mathrm{~nm}$ emission band probably because of a weak crystal field and also strong-electronphonon coupling on this $\mathrm{p} \rightarrow \mathrm{s}$ transition. However, the $690 \mathrm{~nm}$ feature which also has multiple decay components does exhibit some spectral structure. The bandshapes recorded for the $690 \mathrm{~nm}$ emission at two specific temperatures are shown in Fig. 10. At $10 \mathrm{~K}$ while the band is broad, it is clearly asymmetric and cannot be fit with a single Gaussian curve. Based on the results of $\mathrm{Wp}$ lineshape fits ${ }^{10}$ done on highly structured absorption bands of atomic europium in the near-UV, it is known (for details see Paper I) that a phonon frequency of $27 \mathrm{~cm}^{-1}$ exists in the Eu/Ar system. Using this as a fixed parameter, Wp lineshape fits of the $690 \mathrm{~nm}$ band were conducted with just two variables, namely the band ori- gin (or the zero phonon line, ZPL) and the strength of the electron-phonon coupling (the Huang-Rhys factor, S). The resulting simulations, conducted at 10 and $25 \mathrm{~K}$, are shown in Fig. 10 and reveal that the emission is made up of 3 components split by 145 and $150 \mathrm{~cm}^{-1}$. The splitting between the components is approximately the same as what is observed on the near-UV bands analysed recently in Paper I. The fitted curves match the experimental quite well but with relative intensities of 2:2:1 and not the 2:1:1 ratio expected for the $\mathrm{J}=7 / 2$ level. A possible explanation for this is that the emission here actually arises from the $\mathrm{J}=9 / 2$ level of the $z^{10} \mathrm{P}$ state which is predicted by group theory to split into $\mathrm{G}, \mathrm{G}$, and $\mathrm{E}$ states. The issue of the spin-orbit level will be discussed in the next section on state assignments. Thus, a possible reason for the multiple decay components is the existence of three crystal field states derived from a single spin-orbit level. This clearly matches the number of components in the temporal profiles of the emission decay.

\section{B. State assignments}

$y^{8} \mathrm{P}$ state excitation of Eu/RG samples produces emission in four spectral regions. The most conclusive state assignments exist for the bands in the $460 \mathrm{~nm}$ region which, from the spectral location and identification of nanosecond radiative lifetimes, arise from resonance fluorescence of the $y^{8} \mathrm{P}$ state. While the decay characteristics of the bands in the $570 \mathrm{~nm}$ region are complex (possibly due to crystal field splitting of the $J=7 / 2$ level) the observation of direct excitation of the $z^{6} \mathrm{P}$ state provides a conclusive assignment of the emission in this region also. The next set of bands which can be assigned with confidence are those in the $800 \mathrm{~nm}$ region. From their location, long decay times and temperature dependence, these bands are attributed to the emission of the metastable $a^{10} \mathrm{D}$ electronic state. This then leaves assignments to be made for the weakest set of bands - those in the $680 \mathrm{~nm}$ region. Two possible assignments can be made here namely, either to the $a^{8} \mathrm{D}_{5 / 2}$ state, red-shifted from $656 \mathrm{~nm}$ or to the $z^{10} \mathrm{P}_{7 / 2}$ state, blue-shifted from $710 \mathrm{~nm}$. Because the occurrence of this matrix band is limited - it is only present for the red and blue sites in $\mathrm{Ar}$, for just the blue site in $\mathrm{Kr}$ and absent in $\mathrm{Xe}-$ the extent of spectral shifting cannot be used as a reliable aid in making an assignment. On the other hand, the high quality lifetime data extracted for this band in Ar points to it being the $z^{10} \mathrm{P}$ state and from the results of the $\mathrm{Wp}$ lineshape fit done on Eu/Ar (shown in Fig. 10) it is possible that the J value is $9 / 2$. The former transition to the ground state occurs at $14563.57 \mathrm{~cm}^{-1}$ in the gas phase. While this is not the lowest energy of the three spin-orbit levels (the $J=7 / 2$ is) it is a $\Delta \mathrm{J}$ allowed transition and actually is the shortest lived as is evident in Table II where the lifetime is quoted as $1.25 \mu$ s. This transition is located at $686.64 \mathrm{~nm}$ in the gas phase indicating that the matrix band is essentially unshifted.

\section{Site dependence of $P$ type $\left[4 f^{7} 6 s^{1} 6 p^{1}\right]$ luminescence - the $y^{8} \mathrm{P}, z^{6} \mathrm{P}$ states}

By focusing on the resonance $y^{8} \mathrm{P}$ state fluorescence, statements can be made regarding the effects of the 


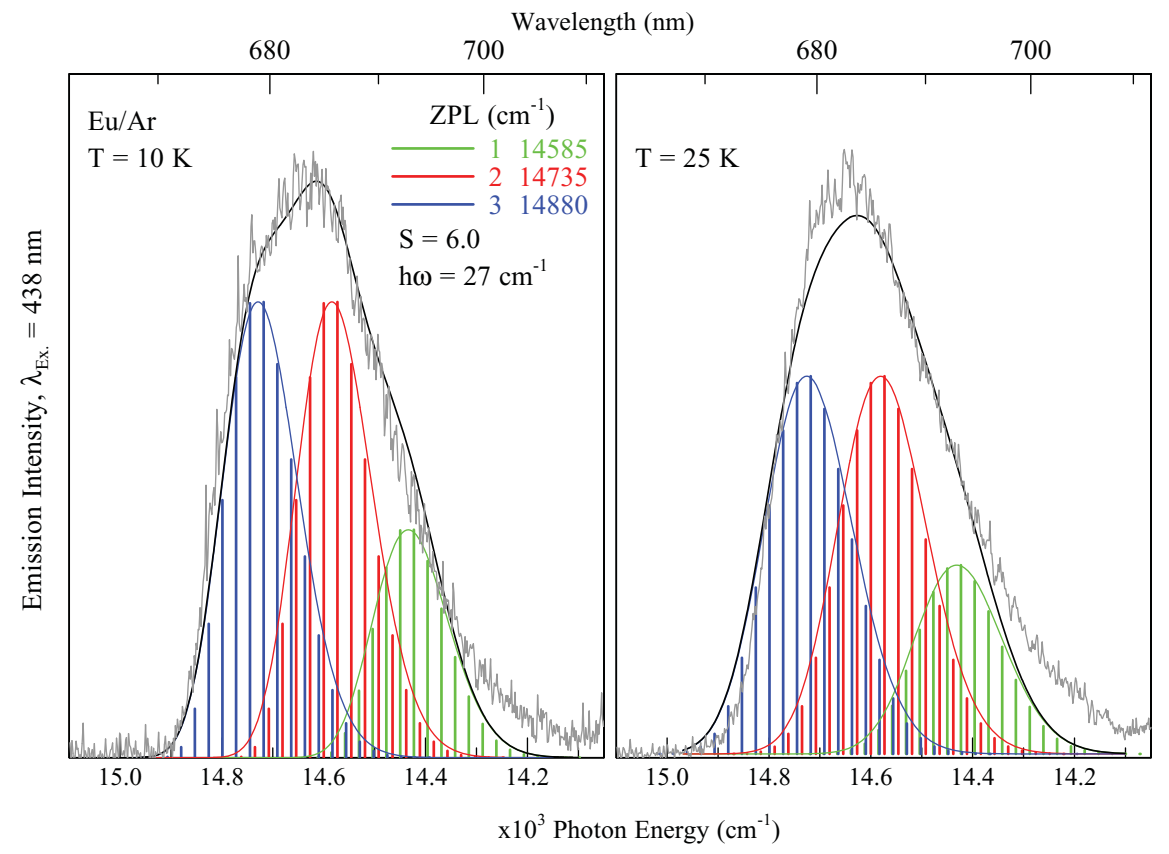

FIG. 10. Simulations of the partially resolved features on the $680 \mathrm{~nm}$ emission band in Eu/Ar generated with the Wp lineshape functions with $\mathrm{S}=6$ and $\mathrm{h} \omega$ $=27 \mathrm{~cm}^{-1}$ for 10 and $25 \mathrm{~K}$. The locations of three zero phonon lines (ZPL) are indicated as 1,2 and 3 - their values are given in wavenumber units. Noteworthy is the intensity ratios of 2:2:1 appropriate for a $J=9 / 2$ level split by a crystal field of cubic symmetry.

different site types on the europium atom in the solid rare gases. Table III collects the spectral and temporal properties of the $y^{8} \mathrm{P}$ state transition in both sites and in the three lattices. The Stokes shift (SS) (calculated from emission band maximum to central Jahn-Teller excitation component) observed in the two site types is markedly different. Thus, the blue site exhibits a SS approximately twice that of atoms in the red site of isolation, implying there is greater short-range repulsive interactions of the guest with the surrounding host in the former site. This is in agreement with our previous site attributions as the blue site being smaller than the red site (see Paper I).

The true radiative decay of the $y^{8} \mathrm{P}$ state fluorescence has been identified for $\mathrm{Eu}$ isolated in the red site yielding lifetimes, which when corrected for the effective field of the surrounding matrix, are in good agreement with the gas phase value of the $y^{8} \mathrm{P} \leftrightarrow{ }^{8} \mathrm{~S}$ transition. However, the radiative lifetime of the $y^{8} \mathrm{P}$ state transition in the blue site of isolation could not be identified implying that even at $10 \mathrm{~K}$ nonradiative relaxation processes are competing quite effectively with the $y^{8} \mathrm{P}$ state fluorescence. Efficient relaxation to lower energy excited states in the blue site is also evident in the strong intensity decrease of the $y^{8} \mathrm{P}$ fluorescence band observed at elevated temperatures. Only a $1 \%$ decrease occurs in emission strength for guest atoms in the red site when the sample temperature is raised from 10 to $14 \mathrm{~K}$. In contrast, $\mathrm{Eu}$ atoms isolated in the blue site loose $y^{8} \mathrm{P}$ emission intensity by a factor of thirty three times more than this. Even in this small $(4 \mathrm{~K})$ temperature range, non-radiative relaxation pathways are competing very efficiently with the $y^{8} \mathrm{P} \rightarrow a^{8} \mathrm{~S}$ fluorescence for atoms in the blue site of isolation. In contrast, such pathways are absent for atoms in the red site.

TABLE III. Photophysical characteristics of the $y^{8} \mathrm{P}$ state emission features from the thermally stable blue and red sites of isolation in Eu/RG. The spectral position is quoted in $\lambda(\mathrm{nm})$ and $v\left(\mathrm{~cm}^{-1}\right)$. The bandwidth (fwhm) is denoted as $\Delta$. Gas phase to matrix frequency shifts for the assigned transition, $\delta$, are displayed in wavenumber units. The observed lifetimes recorded in the matrix at $10 \mathrm{~K}$ are labelled $\tau_{10 \mathrm{~K}}$ and where the radiative lifetime is identified $\left(\tau_{\text {rad }}\right)$ values are corrected for the effective field of the surrounding matrix ( $\tau_{\text {Cor }}$ ). The magnitude of the Stokes shift (SS) between the central Jahn-Teller excitation component and the emission band is quoted in $\mathrm{cm}^{-1}$.

\begin{tabular}{lcccccccc}
\hline \hline & \multicolumn{7}{c}{ Eu/RG $-\boldsymbol{y}^{\mathbf{8}} \mathbf{P}$ resonance fluorescence } \\
\cline { 2 - 8 } Host & $v\left(\mathrm{~cm}^{-1}\right)$ & $\lambda(\mathrm{nm})$ & $\Delta\left(\mathrm{cm}^{-1}\right)$ & $\delta\left(\mathrm{cm}^{-1}\right)$ & $\tau_{10 \mathrm{~K}}(\mathrm{~ns})$ & $\tau_{\mathrm{rad}}(\mathrm{ns})$ & $\tau_{\text {Cor }}(\mathrm{ns})$ & $\mathrm{SS}\left(\mathrm{cm}^{-1}\right)$ \\
\hline Gas Phase $^{2}$ & 21444.58 & 466.3 & $\ldots$ & $\ldots$ & 7.7 & 7.7 & 7.7 & $\ldots$ \\
Red Site & & & & & & & & \\
$\mathrm{Ar}$ & 21867 & 457.3 & 167 & +422 & $3.5 \mathrm{~ns}$ & $\checkmark$ & 7.2 & 351 \\
$\mathrm{Kr}$ & 21352 & 468.3 & 127 & -92 & $3.5 \mathrm{~ns}$ & $\checkmark$ & 9.1 & 292 \\
Blue Site & & & & & & & & \\
$\mathrm{Ar}$ & 22141 & 451.6 & 192 & +697 & $2.3 \mathrm{~ns}$ & $\mathrm{X}$ & $\ldots$ & 674 \\
$\mathrm{Kr}$ & 21523 & 464.6 & 108 & +78 & $1.65 \mathrm{~ns}$ & $\mathrm{X}$ & $\ldots$ & 657 \\
$\mathrm{Xe}$ & 20707 & 483 & 268 & -737 & $2.8 \mathrm{~ns}$ & $\mathrm{X}$ & $\ldots$ & 769 \\
\hline \hline
\end{tabular}




\section{D. $z^{6} \mathrm{P}$ state Lifetime}

With the excitation bands of the $z^{6} \mathrm{P}$ state identified, an investigation of this feature's emission decay profile was possible through the simplest relaxation pathway, namely direct resonance excitation. The decay times obtained in this way are comparable to those produced with indirect $y^{8} \mathrm{P}$ state excitation. However, they are considerably shorter than the gas phase value quoted for the $z^{6} \mathrm{P}$ state in Table II. The NIST Atomic Spectra Database references work from 1975, but more recent gas phase lifetime measurements of this and other $\mathrm{P}$ states of atomic $\mathrm{Eu}$ are now available. The most recent study ${ }^{15}$ identified a lifetime of $870 \pm 44$ ns for the $z^{6} \mathrm{P}_{7 / 2}$ $\leftrightarrow a^{8} \mathrm{~S}_{7 / 2}$ transition using laser induced fluorescence. Clearly there is a discrepancy between the solid state and the gas phase lifetimes recorded. This may be due in part to vibronic enhancement of the transition probability in the solid state and also some inaccuracies of the gas phase lifetimes recorded to date. It is noteworthy that the most recent gas phase results are becoming shorter and approaching the present matrix results.

\section{E. State dependence of $\mathbf{P}$ type luminescence $\left(y^{8} \mathrm{P}\right.$ and $\left.z^{6} \mathrm{P}\right)$}

The behaviour of the two distinct $\mathrm{P}$ states recorded in excitation spectra and derived from the $4 \mathrm{f}^{7} 6 \mathrm{~s}^{1} 6 \mathrm{p}^{1}$ configuration is compared in Fig. 11 for the blue site of isolation. The excitation/emission spectral features of the three matrix Eu/RG systems are plotted versus their shift from the position of the $y^{8} \mathrm{P}, z^{6} \mathrm{P} \rightarrow a^{8} \mathrm{~S}$ transitions in the gas phase. It is evident that the two states behave very differently. Thus, the $y^{8} \mathrm{P}$ state, shown in the lower panel, exhibits the classic behaviour of a Jahn-Teller (JT) split excitation and an emission band with a large Stokes shift $\left(\mathrm{c}=700 \mathrm{~cm}^{-1}\right)$. In contrast the $\mathrm{z}^{6} \mathrm{P}$ state exhibits less recognisable behaviour. As analysed in Paper I, the excitation structures of this state evolve from a pair of spinorbit levels $(J=7 / 2$ and $5 / 2)$ in Ar to a mixture of JT splitting and a $J=7 / 2$ level in Xe. The matrix excitation bands correspond (both in location and intensity) to the two optically allowed transitions of the spin-orbit levels of the $z^{6} \mathrm{P}$ state.

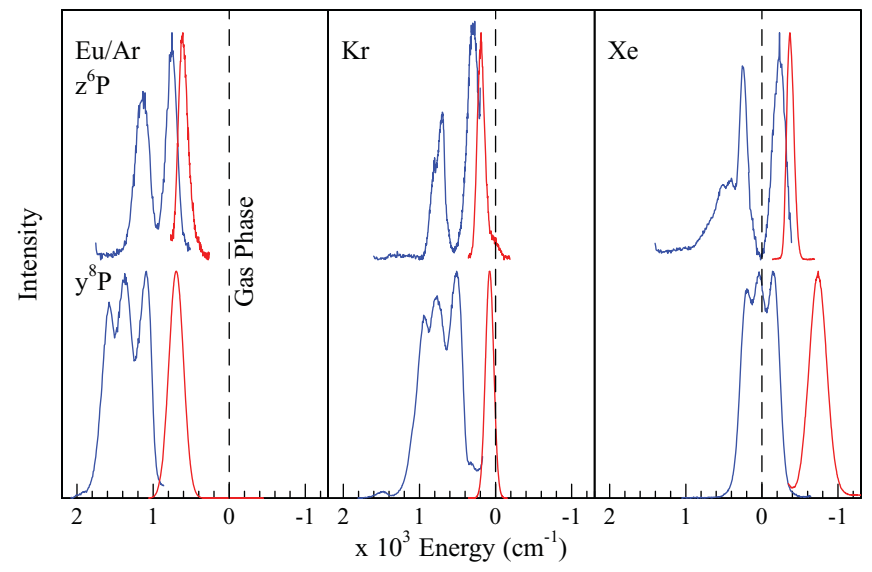

FIG. 11. Excitation and emission spectra of the $z^{6} \mathrm{P}$ (upper traces) and $y^{8} \mathrm{P}$ (lower traces) states recorded for the blue site of the Eu/RG's. The spectra are shown relative to the appropriate gas phase transition where the zero position represents the gas phase transitions involved.
As commented in Paper I, the co-existence of spin-orbit and Jahn-Teller (S.O. + J.T.) coupling is an unusual situation but it has been observed and is well documented in the case of the ${ }^{2} \mathrm{P}$ absorption of matrix-isolated atomic silver. ${ }^{11,12} \mathrm{In}$ all three rare gases, emission occurs from the $J=7 / 2$ level of the $z^{6} P$ state and as is very evident in Fig. 11, leads to a small Stokes shift $\left(\mathrm{c}=100 \mathrm{~cm}^{-1}\right)$ and considerable overlap between the excitation and emission bands.

\section{F. Site dependence of $D$ type $\left[4 f^{7} 5 d^{1} 6 s^{1}\right]$ luminescence ( $a^{10} \mathrm{D}$ state)}

Emission from the metastable $a^{10} \mathrm{D}$ state is the best case for analysis of the site dependence of the $4 f^{7} 5 d^{1} 6 s^{1}$ configuration as it is observed for both sites in all hosts. Table IV collates the spectral and temporal data of the $a^{10} \mathrm{D}$ state emission. Evident for the emission from each site is the negligible spectral shift and similar bandwidths between Ar and Kr. Emission occurs at $790 \mathrm{~nm}$ with a width of approximately $210 \mathrm{~cm}^{-1}$ in the red site and in the blue site bandwidths of $280 \mathrm{~cm}^{-1}$ and emission maxima at $815 \mathrm{~nm}$ are observed. $a^{10} \mathrm{D}$ state emission in Xe yields a broader emission feature which is slightly red shifted compared to the corresponding Ar and $\mathrm{Kr}$ features which may be an effect of the increased stabilisation in the larger, more polarisable Xe lattice.

The fact these emissions are broad and considerably shifted from the gas phase position of the corresponding electronic transition as opposed to classically observed $\mathrm{D} \rightarrow \mathrm{S}$ narrow unshifted features will now be addressed. Although D $\rightarrow \mathrm{S}$ transitions are usually expected to be narrow, a study of the D state luminescence of atomic manganese isolated in the solid RG's has shown that the available site size, plays an important role in defining its spectral characteristics. In the case of atomic Mn isolated in solid krypton, ${ }^{13}$ two thermally stable sites of isolation are occupied in the fcc structured lattice, a single-vacancy (sv) site of size $3.99 \AA$ and a larger tetravacancy (tv) with a size of $4.68 \AA$. Mn-Kr has a predicted van der Waals diatomic bond length of $4.54 \AA$ so the tv site can easily accommodate the Mn atom with little distortion of the

TABLE IV. Photophysical characteristics of the $a^{10} \mathrm{D}$ state emission features of the thermally stable blue and red sites of isolation in Eu/RG. The spectral position is quoted in $\lambda(\mathrm{nm})$ and $v\left(\mathrm{~cm}^{-1}\right)$. The bandwidth (fwhm) is denoted as $\Delta$. Gas phase to matrix frequency shifts for the assigned transition, $\delta$, are displayed in wavenumber units. The observed lifetimes recorded in the matrix at $10 \mathrm{~K}$ are labelled $\tau_{10 \mathrm{~K}}$.

\begin{tabular}{lccccc}
\hline \hline & \multicolumn{5}{c}{ Eu/RG-a $\boldsymbol{a}^{\mathbf{1 0}} \mathbf{D} \rightarrow \boldsymbol{a}^{\mathbf{8}} \mathbf{S}_{7 / \mathbf{2}}$ phosphorescence } \\
\cline { 2 - 6 } Host & $\nu\left(\mathrm{cm}^{-1}\right)$ & $\lambda(\mathrm{nm})$ & $\Delta\left(\mathrm{cm}^{-1}\right)$ & $\delta\left(\mathrm{cm}^{-1}\right)$ & $\tau_{10 \mathrm{~K}}(\mathrm{~ms})$ \\
\hline Gas Phase $^{\mathrm{a}}$ & 12923.7 & 773.77 & $\ldots$ & $\ldots$ & $\ldots$ \\
Red Site & & & & & \\
$\mathrm{Ar}$ & 12649 & 790.6 & 203 & -275 & $0.7,2.1$ \\
$\mathrm{Kr}$ & 12671 & 789.2 & 217 & -253 & $0.8,2.2$ \\
Blue Site & & & & & \\
$\mathrm{Ar}$ & 12281 & 814.3 & 281 & -643 & $0.4,1.3$ \\
$\mathrm{Kr}$ & 12262 & 815.5 & 285 & -662 & $0.8,2.4$ \\
$\mathrm{Xe}$ & 12145 & 823.4 & 367 & -779 & 1.2 \\
\hline \hline
\end{tabular}

${ }^{\mathrm{a}}$ Reference 2 . 
lattice site. Conversely, when the Mn atom exists in the sv site, considerable distortion results from accommodating the guest atom, causing a strong interaction between the guest $\mathrm{Mn}$ and the surrounding lattice. The differing strengths of short range Mn-RG interactions in each of these spatially distinct lattice surroundings, manifests itself in the luminescence observed from D type excited states. When the guest atoms cause little lattice distortion, D states show the classically expected narrow and unshifted spectral features. Thus for $\mathrm{Mn}\left({ }^{6} \mathrm{D}\right) / \mathrm{Kr}$ in a tv site, a narrow bandwidth of $65 \mathrm{~cm}^{-1}$ and small matrix shift of $-18 \mathrm{~cm}^{-1}$ is observed. ${ }^{14}$ However, $\mathrm{Mn}\left({ }^{6} \mathrm{D}\right) / \mathrm{Kr}$ sv site emission is considerably broadened and shifted, a bandwidth of $260 \mathrm{~cm}^{-1}$ and matrix shift of $-1097 \mathrm{~cm}^{-1}$ are identified.

When these observations are applied to the case of $\mathrm{Eu} / \mathrm{RG}$, neither the blue or red sites proposed to be tv and hv sites can accommodate the Eu guest without significant site distortion. This can be seen by consulting Table IV in Paper I. The large site distortion involved in accommodating the large Eu atom results in un-classical broad and shifted D state emission.

\section{CONCLUSIONS}

The luminescence produced with $y^{8} \mathrm{P}$ state excitation of atomic Eu in rare gas matrices is complex arising from multiple site occupancy in the RG lattices and numerous emission features. Using site-specific excitation the current study has simplified the spectroscopy allowing identification of emission from just two thermally stable sites of isolation in solid $\mathrm{Ar}$ and $\mathrm{Kr}$ and only one site in the Xe host. Each site produces emission from four excited states. The expected $y^{8} \mathrm{P}$ fluorescence is identified and based on their spectral shifts and recorded lifetimes, emission from the $z^{6} \mathrm{P}$, and $a^{10} \mathrm{D}$ states are also involved. The weakest bands in the rare gas systems, at $690 \mathrm{~nm}$, are tentatively assigned to the $z^{10} \mathrm{P}$ state.

A recurring observation in the present work is the occurrence of multiple components in the recorded decay profiles of all the emission bands except resonance fluorescence of the $y^{8} \mathrm{P}$ state. This behaviour has been attributed to the existence of multiple crystal field levels arising from the splitting of the distinct spin-orbit levels from which emission occurs. The crystal field splittings extracted in $\mathrm{Wp}$ lineshape fits of the $690 \mathrm{~nm}$ bands were 150 and $145 \mathrm{~cm}^{-1}$, values in close agreement with those recently extracted in Paper I from fits of highly resolved absorption bands in the near-UV.

Analysis of the Stokes shifts values observed for the $y^{8} \mathrm{P}$ state in each site supported the site attributions made in Paper I, whereby the smaller blue tv site, having a greater repulsive interaction with the guest, is manifested as a larger Stokes shift. In addition, the red and blue sites exhibit very different temperature dependence both spectrally and temporally. The blue site loses intensity and its temporal profiles shorten dramatically between 10 and $16 \mathrm{~K}$ indicating very efficient non-radiative relaxation for the $y^{8} \mathrm{P}$ state in this site.

$z^{6} \mathrm{P}$ state emission is identified in the $570 \mathrm{~nm}$ region. Lifetimes produced with indirect $y^{8} \mathrm{P}$ state excitation and direct $z^{6} \mathrm{P}$ state excitation yielded little difference revealing the intervening $y^{8} \mathrm{P} \rightarrow z^{6} \mathrm{P}$ feeding step is very fast. However, the lifetimes recorded in the matrix do not agree with gas phase decay data published on this state. In the most recent literature, the gas phase values are becoming closer to the solid state value measured here.

The lowest energy Eu/RG emission is observed in the $800 \mathrm{~nm}$ region. It is also the longest-lived with matrix values of several milliseconds and is thereby assigned to the metastable $a^{10} \mathrm{D}$ state. This assignment is supported by a temperature dependence study, which shows an increase in population for this state at elevated temperatures implying it is acting as a "population trap." These are the first recorded lifetime values for this electric-dipole forbidden transition of atomic Eu which has not been measured in the gas phase. $\mathrm{D} \rightarrow \mathrm{S}$ type emission of atomic europium show little host change effects on their spectral location. However, unlike "classical" $D \rightarrow S$ transitions they are broad and shifted from the gas phase position. This is an example of the effect of site size on D states of metal atom systems. The large guest europium causes significant site distortion in occupying the available vacancies of the RG solids causing broad and shifted D state emission. This effect may be characteristic of lanthanide guest atoms and warrants analysis of other f-block systems.

\section{ACKNOWLEDGMENTS}

This research was funded by the Embark Initiative Irish Research Council for Science, Engineering and Technology (IRCSET) and a John \& Pat Hume scholarship from N.U.I. Maynooth to whom OB gratefully acknowledges receipt of a Ph.D. studentship. The iCCD camera used in this work was acquired with the financial support of Science Foundation Ireland (SFI), Investigator Grant 02/IN.1/B032.

${ }^{1}$ O. Byrne and J. G. McCaffrey, J. Chem. Phys 134, 124501 (2011)

${ }^{2}$ NIST Atomic Spectra Database (version 3.1.5), August 2010 (National Institute of Standards and Technology, Gaithersburg, MD). Available: http://physics.nist.gov/asd3.

${ }^{3}$ M. A. Collier and J. G. McCaffrey, J. Chem. Phys. 119, 11878 (2003).

${ }^{4}$ Owen Byrne, $\mathrm{PhD}$ dissertation, National University of Ireland Maynooth, 2009, http://eprints.nuim.ie/2439/.

${ }^{5}$ R. L. Fulton, J. Chem. Phys. 61, 4141 (1974).

${ }^{6}$ T. Shibuya, J. Chem. Phys. 78, 5175 (1983).

${ }^{7}$ The refractive indices of $\mathrm{Ar}, \mathrm{Kr}$, and $\mathrm{Xe}$ are $1.29,1.28$, and 1.49 recorded at $60 \mathrm{~K}$ and $\lambda=488 \mathrm{~nm}$ from H. J. Jodl, Solid State Aspects of Matrices in The Chemistry and Physics of Matrix-Isolated Species (North-Holland, Amsterdam, 1989); The index of refraction used for solid Ar at $233 \mathrm{~nm}$ is 1.32 at $6 \mathrm{~K}$, that of $\mathrm{Kr}$ is 1.428 at $241 \mathrm{~nm}$ at $12 \mathrm{~K}$ [P. Gurtler (1996, unpublished)].

${ }^{8}$ C. Crepin-Gilbert and A. Tramer, Int. Rev. Phys. Chem. 18, 485 (1999).

${ }^{9} \mathrm{~A}$ minor amount of thermally unstable site emission (U) is also observed due to some residual atoms remaining in this site following sample annealing.

${ }^{10} \mathrm{C}$. W. Struck and W. H. Fonger, Understanding Luminscence Spectra and Efficiency Using Wp and Related Functions (Springer-Verlag, Berlin, 1991).

${ }^{11}$ H. Wiggenhauser, W. Schroeder, and D. M. Kolb, J. Chem. Phys. 88, 3434 (1988).

${ }^{12}$ K. Bammel, P. Dietrich, and N. Schwentner, J. Chem. Phys. 111, 2123 (1999).

${ }^{13}$ M. A. Collier and J. G. McCaffrey, J. Chem. Phys. 122, 184507 (2005).

${ }^{14}$ M. A. Collier, M. C. Ryan, and J. G. McCaffrey, J. Chem. Phys. 123, 044508 (2005).

${ }^{15}$ E. A. Den Hartog, M. E. Wickliffe, and J. E. Lawler, Astrophys. J., Suppl. Ser. 141, 255 (2002).

${ }^{16}$ N. P. Penkin, V. N. Gorshkov, and V. A. Komarovsky, Opt. I Spektroskopiya 57, 803 (1984). 